\title{
A System Dynamics Simulation to Estimate Roundabout Entry Capacity by Adopting Three Different Methods
}

\author{
Raquim N. Zehawi, Qusay W. Ahmed \\ Department of Civil Engineering, College of Engineering, University of Diyala \\ raquim_zehawi@yahoo.com, msc.qussaay@yahoo.com
}

\begin{abstract}
Many models were introduced to estimate the roundabout entry capacity from 1980s until now. In the United States, transportation agencies adopted three different models from 1994 until 2010. The Austroads, the UK, and the HCM 2010 methods. In this paper, these three methods were used to analyze the field traffic data of Al-Quds roundabout, located near Baqubah City, simultaneously by utilizing a system dynamics model. The collected data included turning movements, circulating flows, and field calculated entry capacities whenever possible during the observation period which lasted for 14 consecutive hours. A comparison is then conducted on the resulting entry capacities and their variation over time. The results showed that the calculated capacity according to Austroads method is the highest at all times while the UK method was always a little lower and the HCM 2010 method was always the least on all entries. The UK method capacity estimates were the closest to the field measured capacities for they returned the least RMSE on all entries. Field capacities showed some tendency towards the Austroads results in the north and south bound entries which carry about $66 \%$ of the total traffic. While, field capacities showed more proximity towards the HCM capacity results in the east and the west bound entries which carry $34 \%$ of the total traffic.
\end{abstract}

Keywords: Roundabout, System Dynamics, Capacity, Traffic Simulation.

Paper History: (Received: 13/3/2017; Accepted: 2/7/2017)

1.Introduction

In pursue of analyzing traffic in roundabouts, many formulas were introduced to assess entry capacity and estimating the level of performance by one or more measure of effectiveness of roundabouts such as degree of saturation, delay, or queue length. Different models usually yield different results and sometimes these differences could be pronounced especially when applying a model that has been developed in a far different environment with respect to transportation facilities and drivers behavior. It has been widely acceptable to utilize the American Highway Capacity Manual (HCM) in analyzing local transportation facilities, but there is quite scarce number of researches that deal with roundabout analyses and much less in calibrating various models with the local traffic characteristics.

The objective of this paper is to analyze the performance of Al-Quds roundabout in terms of entry capacities and the degree of saturation by using three different methods, each one of them was once adopted by the American Transportation Research Board (TRB) for a certain period of time. These three methods were incorporated in a system dynamics simulation model in which the formula of each capacity model is inserted as well as the collected traffic data to perform the calculation processes and then producing several comparative graphical presentations of the model outcomes through the use of the assisting features of system dynamics that provide the capability of executing these types of calculations and presentations in an easy and comprehensive manner. A comparison between the different methods results and the field measured capacities may shed some light on the manner in which a better representative capacity model with respect to our local traffic characteristics could be chosen to analyze local roundabouts.

\section{Literature Review}

Many mathematical models were introduced to analyze the performance of roundabouts since 1980s until now. The early procedures for estimating the capacity performance were represented by analytical models which are generally based on the conflicting circulating flow and two gap acceptance parameters: critical gap and follow-up time [1], while many resent analyses are conducted by empirical models, typically generated by regression 
analyses through the utilization of field traffic and geometry data. These models often relate the entry capacity to the circulating flow as well as the geometric design of the roundabout [2]. However, at high levels of conflicting flow other capacity mechanisms occur and a simplified gap acceptance model may not give reliable results[1].

Roundabout capacity models vary a great deal from an agency to another depending on the country in which the model has been developed and the extent to which the roundabout are frequent in their roadway system and the degree to which their drivers are accustom to the proper driving behavior in such intersections. It is quite acceptable for any agency to adopt a model that was developed by another one in another country. In the United States, until 1997, there were two primary methods and software programs used; the Australian method in which the SIDRA software is used and the British method which utilizes either the RODEL or the ARCADY software [3]. Nevertheless; the use of two or more models to analyze traffic operations in a roundabout may yield different results especially with different derivation background. This may necessitate a comparison of the results of the applied models in reference to the actual traffic behavior in the existing roundabout.

In many studies, practical models to test operations at alternative roundabout configurations where isolated intersection analysis was conducted by the empirical model (RODEL) which was developed based on regression [4], and the analytical model (SIDRA) [5] software, and further supplemented with a site-wide (VISSIM) model [6]. Their results usually are different and comparative analyses mostly conducted between their estimated capacities and field data. There was always the arising debate regarding the accuracy of these software, in general; they overestimate the capacity with a noticeable proximity of the VISSIM results to field capacities [7,8], but it was proven that when they are used in combination they served the purpose of the study [9].

The early system dynamics simulation models in transportation were introduced some twenty five years ago, particularly for aggregate longterm situations, for economic trip forecasting scenarios or for modelling the interaction between transport and land use [10]. The fact that the apparent stability of travel behavior conceals considerable variation in individual behaviors; furthermore, changes in these behaviors in response to various stimuli are not instantaneous but take place with delay [11]. It was also proven that "The simulation model allows the deficiencies of the real system to be identified", and "it was possible to propose alternatives for improvement without incurring the high costs of implementation" [12].

Xue \& Hudson 2004, developed a basic system dynamics model that simulates traffic flow in a basic road section and a three leg roundabout. Their conclusion stated that the most distinct advantage of using system dynamics models is the "ease in which features can be changed, so allowing the rapid prediction of different results [13].

\section{Roudabout Traffic Operational Analyses}

As stated earlier; the operational analysis produces two kinds of estimates: the first is the capacity of a facility while the second is the level of performance, usually measured in one or another term of effectiveness, such as degree of saturation, delay or queue length [14].

The first operational model to be discussed is the one developed in 1980 in the United Kingdome, and the second model is the one developed in Australia in 1993. Both models were adopted once in the United States before the development of their own model which is the third one to be included in this paper as Highway Capacity Manual (HCM 2010) model.

\subsection{Capacity}

There are two factors affecting the maximum flow rate that can be accommodated at a roundabout entry, the first is the circulating flow on the roundabout roadway that conflicts with the entry flow, and the second is the geometric elements of the roundabout. When the circulating flow is low, the gaps are more useful to the entering drivers and more than one vehicle may enter each gap. As the circulating flow increases, the size of the gaps in the circulating flow decrease, and the rate at which vehicles can enter also decreases. All entry capacity models deal with this concept and utilize both influencing factors but with different manner depending on the environment in which the model was developed [14].

\subsubsection{The highway capacity manual method.} The Highway Capacity Manual (HCM 2010) adopts simple regression models to assess roundabout entry capacity. The circulating conflicting flow is mentioned in the mathematical formula in all these models, while the geometric characteristics are taken under consideration by classifying roundabouts according to them.

The capacity of an entry lane opposed by one circulating lane such as a one-lane entry to a one-lane roundabout, or either lane of a twolane entry conflicted by one circulating lane . 
The equation for estimating the capacity is given as Equation 1, but if a one-lane roundabout entry opposed by two conflicting lanes, the capacity is given as in Equation 2, while Equation 3 and Equation 4 give the capacity of the right and left lanes, respectively, of a two-lane roundabout entry opposed by two conflicting lanes [14], the curves of these equations is shown in Figure 1.

$$
\left.C_{e, p c e}=1130 e^{\left(-1.0 \times 10^{-3}\right.}\right) v_{c, p c e}
$$

Where:

$C_{e, p c e}=$ Lane capacity, adjusted for heavy vehicles, $\mathrm{pc} / \mathrm{h}$; and

$v_{c, p c e}=$ Conflicting flow, $\mathrm{pc} / \mathrm{h}$.

$$
\begin{aligned}
& C_{e, p c e}=1130 e^{\left(-0.7 \times 10^{-3}\right)} v_{c, p c e} \\
& C_{e, R, p c e}=1130 e^{\left(-0.7 \times 10^{-3}\right)} v_{c, p c e} \\
& \left.C_{e, L, p c e}=1130 e^{\left(-0.75 \times 10^{-3}\right.}\right) v_{c, p c e}
\end{aligned}
$$

Where:

$C_{e, R, p c e}=$ Capacity of the right entry lane, adjusted for heavy vehicles, $\mathrm{pc} / \mathrm{h}$;

$C_{e, L, p c e}=$ Capacity of the left entry lane, adjusted for heavy vehicles, $\mathrm{pc} / \mathrm{h}$; and $v_{c, p c e}=$ conflicting flow, $\mathrm{pc} / \mathrm{h}$.

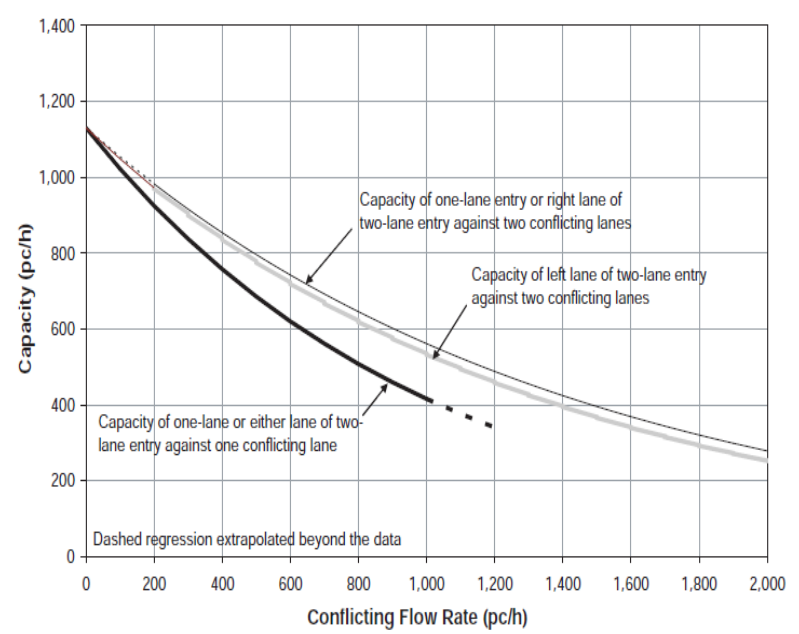

Figure 1: Entry Lane Capacity HCM 2010

\subsubsection{The U.K. empirical model}

In the United Kingdom, the effort was oriented over nearly 12 years towards developing a roundabout capacity model that is easily used in design process and satisfies the intersections operational requirements in the same time. The endeavor produced a high definition, robust and dependable regression model that gives a practical links between geometry and capacity, delay and queuing. The model was developed by R. M. Kimber in 1980 [15].
The model formula is a linear relation between the entry capacity and circulatory flow and six geometric parameters. The equation of this model is as follows:

$$
\begin{aligned}
& Q_{e}=K\left(F-f_{c} Q_{c}\right), f_{c} Q_{c} \leq F(5) \\
& Q_{e}=0 \quad f_{c} Q_{c}>F \\
& K=1-0.00347(\varnothing-30)-0.978\left(\frac{1}{r}-0.05\right)(6) \\
& F=303 x_{2} \quad(7) \\
& f_{c}=0.210 t_{D}\left(1+0.2 x_{2}\right)(8) \\
& t_{D}=1+\frac{0.5}{1+\exp \left(\frac{D-60}{10}\right)} \\
& x_{2}=v+\frac{e-v}{1+2 S} \\
& S=\frac{1.6(e-v)}{l^{\prime}}
\end{aligned}
$$

Where:

$Q_{e}=$ entry capacity, pce $/ \mathrm{h}$

$Q_{c}=$ circulating flow, $\mathrm{pce} / \mathrm{h}$

$e=$ entry width, $\mathrm{m}$

$v=$ approach half width, $\mathrm{m}$

$l^{\prime}=$ effective flare length, $\mathrm{m}$

$S=$ sharpness of flare, $\mathrm{m} / \mathrm{m}$

$D=$ inscribed circle diameter, $\mathrm{m}$

$\varnothing=$ entry angle, ${ }^{\circ}$

$r=$ entry radius,

Many agencies tabulate roundabouts according to their geometry. The informational guide of the Federal Highway Administration FHWARD-00-067 classifies roundabouts into six categories depending mainly on their inscribed circle diameters listed in Table 1.

Other geometrical characteristics are usually distinguished in each categories layout details. It should be noted that the dimensions of roundabouts may vary considerably within each category, depending on site-specific characteristics, including number of legs, approach angles, out of limits inscribed circle, and so on. A comparison between the expected capacities of single and double lane roundabouts is shown in Figure 2 [16].

Table 1 Typical inscribed circle diameter ranges by roundabout category. Source [16].

\begin{tabular}{|c|c|}
\hline Site Category & Inscribed Circle Diameter Range \\
\hline Mini roundabout & $13-15 \mathrm{~m}$ \\
\hline Urban compact & $25-30 \mathrm{~m}$ \\
\hline Urban single lane & $30-40 \mathrm{~m}$ \\
\hline Urban double lane & $45-55 \mathrm{~m}$ \\
\hline Rural single lane & $35-40 \mathrm{~m}$ \\
\hline Rural double lane & $55-60 \mathrm{~m}$ \\
\hline
\end{tabular}




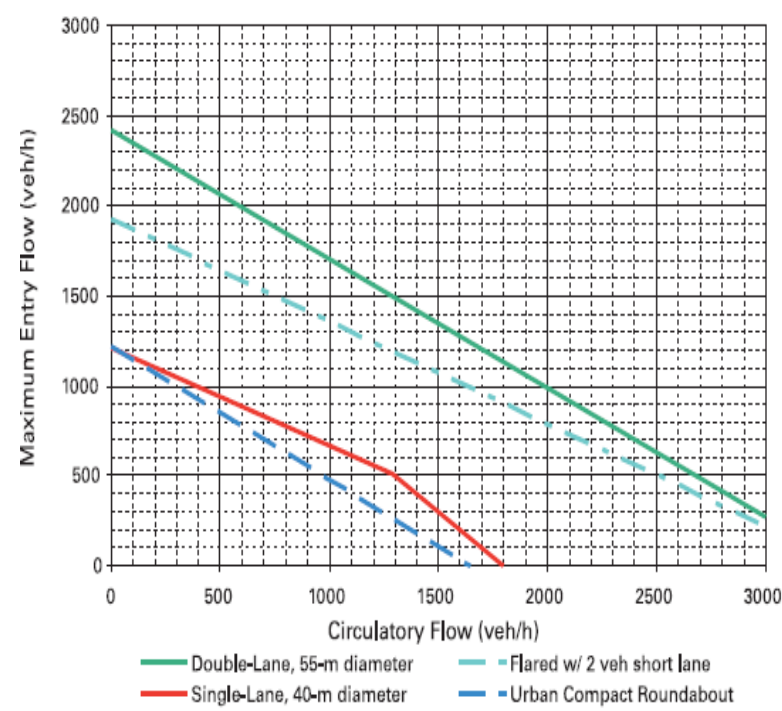

Figure (2): Capacity comparison of single \& double-lane roundabouts, UK method. Source[16]

\subsubsection{The Austroads 1993 Manual Method}

The Australian method distinguishes for multiple-lane entries between the dominant stream and the sub-dominant stream. The dominant stream is the one with the greatest entry flow. Follow-up times are calculated first for each lane as a function of the inscribed diameter, the number of entering lanes and circulating lanes, and of the circulating flow. Critical acceptance gaps (i.e., the minimum gap acceptable for entry) are dependent on the follow-up time, the circulating flow, the number of circulating lanes, and the average entry lane width. The number of useful gaps depends on the proportion of vehicles that are bunched and the proportion of non-bunched vehicles [17].

The capacity of each entry lane is calculated from the entry lane gap acceptance parameters (ta and tf) applicable to the dominant lane and to each sub-dominant entry lane and the circulating flow characteristics (qc, $\tau$, and $\Theta$ ). The appropriate equation is:

$\boldsymbol{C}=\frac{3600(1-\theta) q_{C} e^{-\lambda\left(t_{a}-\tau\right)}}{1-e^{-\lambda t_{f}}}$

Where:

$C=$ the absorption capacity of an entry lane in veh/h

$\theta=$ the proportion of bunched vehicles in the circulating streams

$q_{c}=$ the flow of vehicles in the circulating streams in veh/s

$t_{a}=$ the critical acceptance gap relevant to the dominant or sub-dominant lanes respectively.

$t_{f}=$ the follow on headway relevant to the dominant or sub-dominant lanes respectively. $\tau=$ the minimum headway in the circulating streams, and these are related by

$$
\lambda=(1-\theta) q_{C} /\left(1-\tau q_{C}\right)
$$

Figure 3 shows simple graphs that can be used to obtain an estimate of roundabout capacity, for a roundabout with two 13 foot wide entry lanes and two circulating lanes.

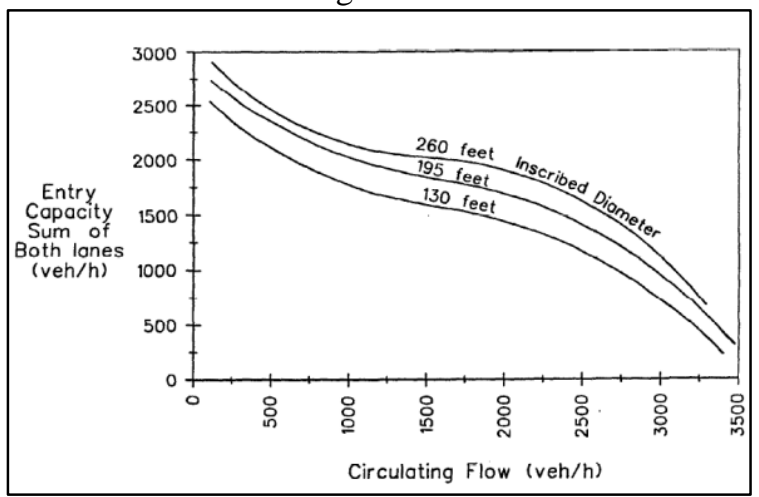

Figure 3: Entry capacity for a 2-circulating lanes and 2-entry $13 \ni l a n e s$ roundabout

\subsection{Performance Analyses}

In assessing the performance of a roundabout design, there are three measures usually utilized; degree of saturation, delay, and queue length. All these measures depend on the capacity of roundabout entry in their computations, but each one of them reflects a distinct perspective on the quality of service at which the roundabout will perform under a given set of traffic and geometric conditions. The attention in this paper will be focused on the degree of saturation on which both delay and queue length are highly dependent.

The degree of saturation is the ratio of the demand at the roundabout entry to the capacity of the entry. It represents a major adequacy measure for the design of the facility in question. Many agencies deal with a degree of saturation of 0.85 as a threshold of satisfactory. When this ratio exceeds this range, it is likely that deterioration in the facilities operations would take place in a very short time. Queues may form and delay increases rapidly. The degree of saturation is calculated by Equation 14.

$$
\text { Where: }
$$

$$
x=v / c
$$

$\mathrm{x}$ : degree of saturation in an entry lane

v: demand flow rate in the entry lane

c: capacity of the entry lane

\section{Case Study}

The roundabout studied in this paper is located some 4 kilometers to the north of Baquba city, the capital of Diyala governorate in the middle of Iraq. It lies at the intersection of two important highways; the East-West axis is the 
highway links Muqdadiyah city with Baghdad, and the north-South axis is the main highway that links Diyala with the northern governorates. Although; the residential areas and commercial businesses are propagating closely to surrounding areas nearby, the roundabout and the connected highways are still considered as rural facilities.

\subsection{Geometry Description}

The roundabout has four nearly geometricallyidentical entries, only the east bound entry has a right-turn double-lane bypass. The bypass is diverged about $125 \mathrm{~m}$ ahead of the east bound entry and it converges with the southern exit about $100 \mathrm{~m}$ downstream. Geometry details of the roundabout are listed in Table 2 and its satellite image is shown in Figure 4.

Table 2 Al-Quds roundabout geometry properties.

\begin{tabular}{|c|c|c|c|c|c|}
\hline Entry & $\begin{array}{c}\text { Entry Width } \\
\text { e (m) }\end{array}$ & $\begin{array}{c}\text { Approach Width } \\
V(\mathrm{~m})\end{array}$ & $\begin{array}{l}\text { Entry Radius } \\
\text { R (m) }\end{array}$ & $\begin{array}{c}\text { Entry Angle } \varnothing \\
(0)\end{array}$ & $\begin{array}{l}\text { Eff. Flare" } \\
\text { Length l' (m) }\end{array}$ \\
\hline $\mathrm{NB}$ & 8 & 8 & 65 & 10 & Non zero \\
\hline WB & 7 & 7 & 45 & 10 & Non zero \\
\hline$S B$ & 7 & 7 & 45 & 10 & Non zero \\
\hline$E B$ & 6 & 6 & 65 & 10 & Non zero \\
\hline \multicolumn{2}{|c|}{ Inscribed Circle } & & & & $110 \mathrm{~m}$ \\
\hline
\end{tabular}

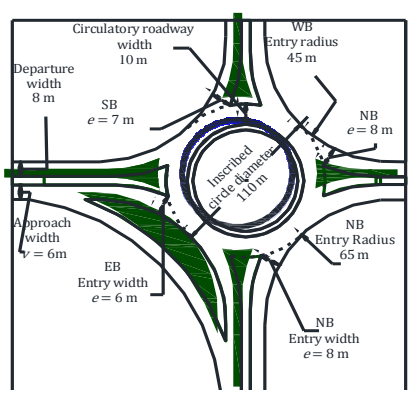

(a) Al-Quds Roundabout Geometry

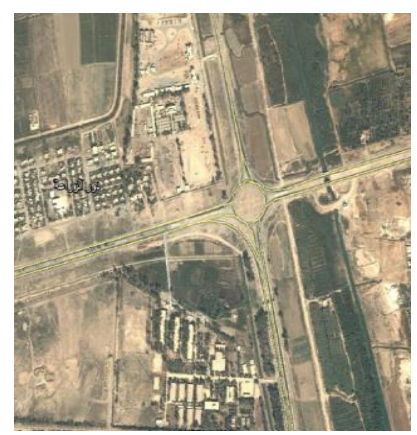

(b) Al-Quds Satellite Image
Figure (4): Al-Quds roundabout

\subsection{Traffic Data Collection}

The traffic data analyzed in this paper was collected in a typical weekday in February 2012, the collection process continued for 14 consecutive hours starting from 5:00 Am until 7:00 Pm. Road tube traffic counters were used to collect the volumes, speeds, and classification of traffic movements in roundabout entries, while digital cameras were utilized to determine the origin destination of vehicles as well as queue length at each entry. Tube counters were mounted at each entry yield line and at each exit. Two parallel tubes one meter spaced at each location were installed and attached to the counting device. Two digital cameras were fitted at elevated levels to secure better video recordings, the first was positioned to the south-east corner and the second to the south-west corner of the roundabout, both mounted some 90 meter horizontally away from the curb of the roundabout and elevated about 4 meters higher than the elevation of the road surface. No cameras were installed in the north-east or north-west due to security reasons and all recording were dependent on the two in the southern sector.

This excessive effort was paid for the benefit of a local authority to assess the need for major renovation to the traffic system in this area at that time. The collected traffic flow data included turning movements, entry flow rates, circulating movements, and entry capacity. Of coerce; the last measurement is the most important one for the operational analyses. It is an applicable procedure to measure field capacity for a given approach in terms of the number of vehicles entering the roundabout when the approach is capacity saturated, i.e. "there were persistent queues of more than 5 vehicles at each lane of the approach during the entire analyses time period" [8].

The level of details in which the specification of traffic volumes are collected provide the capability of converting all vehicle types into passenger car equivalent (pce) in accordance with each one of the models utilized in this paper. Traffic information shows that the morning peak hour lasts from 7:0 to 8:0 AM while the afternoon peak hour lasts from 2:0 to 3:0 PM. Table 3 shows the turning movements in the afternoon peak hour.

The highest volume throughout the observation period was noticed at the south bound entry, less volumes were present at the north and west bound entries respectively, while the least volume was noticed at the east bound entry apparently due to the presence of the right turn bypass. Field capacity was successfully measured in saturation queue minutes which obviously increase as the entry and circulating flow rate increase. These field capacities were measured $26,16,12$, and 8 times in the south, north, east, and west bound entries respectively. 
Table 3 Turning movements at Al-Quds roundabout at the afternoon peak hour.

\begin{tabular}{|c|c|c|c|c|}
\hline \multirow{2}{*}{$\begin{array}{c}\text { Approach } \\
\text { Entry }\end{array}$} & \multicolumn{3}{|c|}{ Tuming Movement(veh $/$ ) } & \multirow{2}{*}{ Total } \\
\cline { 2 - 4 } & Right & Through & Left & \\
\hline NB & 330 & 458 & 558 & 1347 \\
\hline WB & 198 & 624 & 368 & 1190 \\
\hline SB & 1039 & 598 & 1129 & 2766 \\
\hline EB & 0 & 661 & 234 & 895 \\
\hline Total & 1567 & 2342 & 2290 & 6198 \\
\hline
\end{tabular}

\section{System Dynamics Simulation Process}

The system dynamics models provide a very good understanding of the dynamic behavior of systems due to the ability of giving insight into feedback process. It is a methodology whereby complex, and nonlinear interactions in dynamic systems can be understood and analyzed and new structures and policies can be designed to improve the system behavior. It is the result of 'Cross Fertilization' among elements of traditional management, feedback control theory and computer simulation" [20]. The system dynamics method has been utilized in this paper due to its high capability of facilitating the comparison between the outcomes of the different operational analyses procedures at any stage or time within the simulation period. The advanced personal learning edition of Vensim software (Vensim PLE Plus) has been used to develop the simulation model.

The simulation model in this paper deals with the traffic flow data in each entry of the case study roundabout including through, left turn, and right turn movements, which are fed to the model through table look-ups and then calculates the entry and circulating flows as well as entry capacities and degrees of saturation as discussed in the model structure and calculations.

\subsection{Modeling Target}

The target of the system dynamics model is to calculate the elements traffic flow rates in each entry of the analyzed roundabout and then to conduct the performing analyses by calculating the capacity of each entry as well as degree of saturation, delay, and queue length. This analysis is going to be applied in three different procedures, the first; adopting the HCM 2010 model, the second; incorporates the UK empirical model, while the third utilizing the Austroads guide method. A comparison is made between the resulting outcomes in the form of graphical presentation where the results of the three models for each entry capacity and degree of saturation are plotted together to facilitate the comparison process.

\subsection{Modeling Boundaries}

The establishment of system boundaries is regarded as the first step in determining the model configuration. At first; a decision should be made for the nomination of the most useful elements to be incorporated in the model to achieve the stated targets. In this model; all entry flow components are considered as exogenous factors as well as all exiting flows. Entry turning movements are fed as external tables or "Lookups". The roundabout geometry elements are also considered exogenous, and inherently contemplated in due "Auxiliaries" comprising the model. The time boundaries are set to be equal to the traffic observation hours.

\subsection{Causal Relationships}

Causality in system dynamics models may illustrate the true representation of the internal relationships between the elements of the system. The main causal relation in our model includes the entry flow rate which has a positive relation with the circulating flow rate, i.e. either the first adds to the second or change in the first produces a change in the second in the same direction. The circulating flow rate, in turn, has a negative relation with the entry capacity which also has a negative relation with the degree of saturation. The negative relation means that either the first subtracts from the second or, the change in the first produces a change in the second in the opposite direction. A negative relation is also present between the entry flow and the degree of saturation. Figure 5 shows the causal relation between the elements of traffic in each entry in the roundabout.

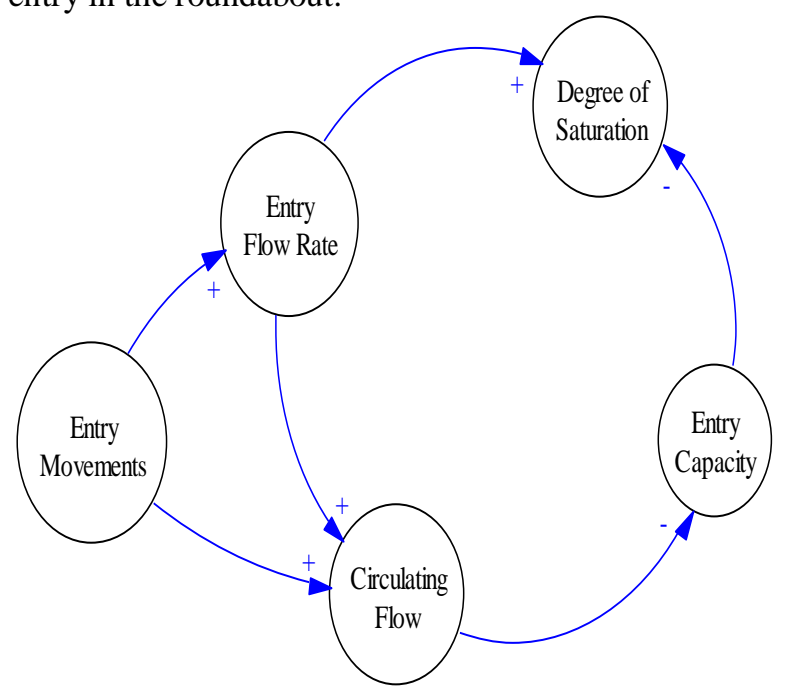

Figure 5: Causal relation of the model elements 


\subsection{Model Structure}

The simulation model has been developed to perform the previously mentioned tasks by encompassing the following elements:

a) Entry turning movements; each entry movement was entered in the form of "Auxiliary with Lookup", this element provides the capability to enter any exogenous factors to the system. The values of the factor are entered either in the form of table or graph, tables are built up with pairs of figures. In activating this type of Auxiliaries with the first figure the Auxiliary yields the second. In this model, the first figure represents the time in all Auxiliaries and all of them are activated by the time variable as shown in the model structure in Figure 6. A sample table of the south bound entry through movement (ST) is as in Equation 15 , in which each pair of information consist of the time in the first and the movement flow rate in the second, the time step is one hour and the total number of pairs is the same as the total duration period in hours.

$S T=W I T H$ LOOKUP (Time, $([(0,0)(18,800)],(1,171),(2,378),(3,652),(4,503$ ) ,

$(5,335),(6,326),(7,424),(8,503),(9,754),(10$ ,734),(11,489),(12,352),(13,466), $(14,553),(15,261),(16,201),(17,118),(18,9$ 9)))

The model has 11 similar Auxiliary representing all entry movements except the East bound write movements which is excluded due to the high speed bypass.

b) Entry flow rate; an Auxiliary is created to account for this variable, each one represents the summation of the entering movements. These variables are; north bound, south bound, east bound, west bound entry flow rates, (NBE), (SBE), (EBE), and (WBE) respectively, each has an equation similar to Eq. 16 of the north bound entry.

$$
\mathrm{NBE}=\mathrm{NL}+\mathrm{NR}+\mathrm{NT}
$$

c) Circulating flow rates; there are four Auxiliaries in this model that calculate the conflicting or circulating flows which are "the sum of the vehicles from different movements passing in front of the adjacent upstream splitter island" (15). A sample mathematical equation of the south bound entry circulating flow is given in Eq. 17, while other circulating Auxiliaries have a similar equation.

NL+WL+WT circulating=
(17)
d) Entry capacities; the capacity for each

d) Entry capacities; the capacity for each
entry is calculated in three different procedures by three variable Auxiliaries, in the first; the HCM 2010 method has been adopted and the capacity formula for the two adjacent entry lanes are calculated as in Equation 18 which characterizes the mathematical formula of the south bound entry capacity according to the HCM method.

"SB Cap.1"= 1130*EXP $((-0.0007) *$ south circulating) $+1130 * E X P$

$((-0.00075) *$ south circulating

(18)

The second variable Auxiliary adopts the UK method in which many geometric features of the roundabout entries are effectively incorporated in capacity formula and they all were taken under consideration in the resulting formula of the Auxiliary as shown in Equation 19 which shows the formula of the south bound capacity following the UK method. Other entries have similar equations with little difference in their factors regarding the geometry in each entry.

"SB Cap.2" = 2326-0.5524*south circulating (19)

The third variable Auxiliary that adopts the Austroads method is designed as Lookup graphs in which each value in the $(\mathrm{X})$ axis represents the circulating flow and its corresponding value in (Y) axis represents the entry capacity, while the geometric properties of the roundabout are taken care of through the choice of the corresponding graph and the proper curve that best represent the entry geometry. Figure 7 illustrates the graph Lookup of the south bound entry capacity. It should be noted that the software also provides a table form of the graph where the first value represents the circulating flow and the second represents the capacity. When the Lookup variable is activated by the values of the circulating flow, it will yield the corresponding value of the entry capacity. Eq. 20 shows the table form of the south bound capacity in its third procedure (SB Cap.3).

"SB Cap.3" = WITH LOOKUP (south circulating, ([(0,0)-(3250,4000)],(250,2725), (500,

470),(750,2280),(1000,2157),(1250,2080),(150 $0,2040),(1750,2009),(2000,1914),(2250,1793)$, $(2500,1615),(2750,1403),(3000,1098),(3250,7$ 09)))

e) Entry degree of saturation; for each entry there are three Auxiliaries each one calculates the degree of saturation depending on the correspondent capacity model. The degree of saturation represents the measure of effectiveness to be considered which reveals the operational sufficiency of this roundabout. The mathematical formula in each one of these Auxiliaries is similar to Equation 21 that donates the saturation degree of the south bound entry measured with respect to the 
capacity according to the HCM method as compared to the entry flow.

"SB Sat.1"= SBE/"SB Cap.1

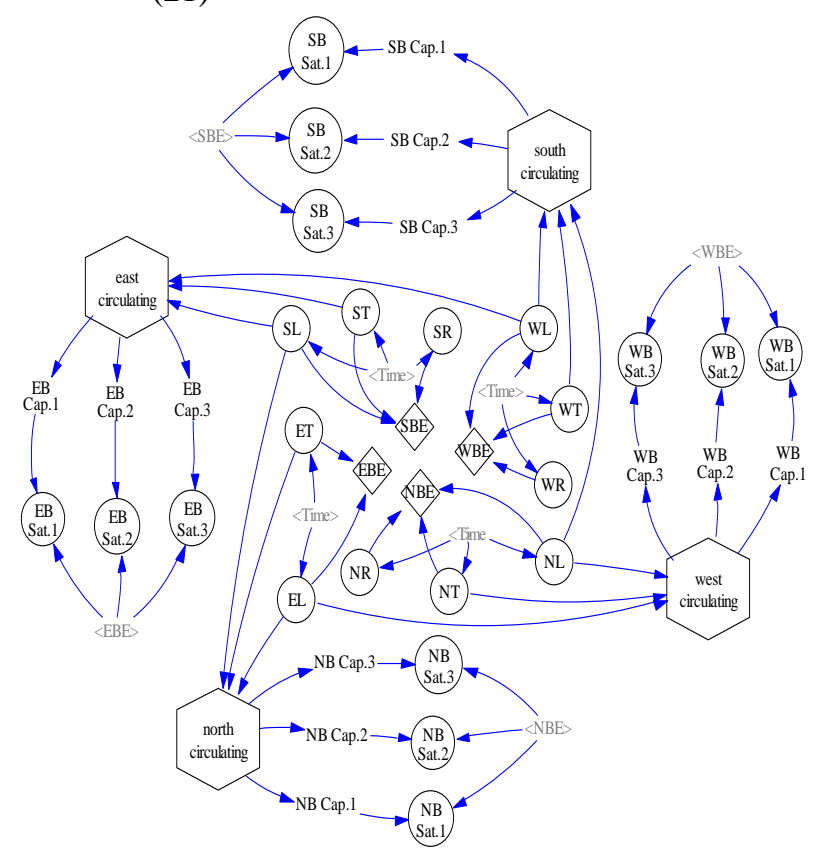

Figure 6: System dynamics model structure

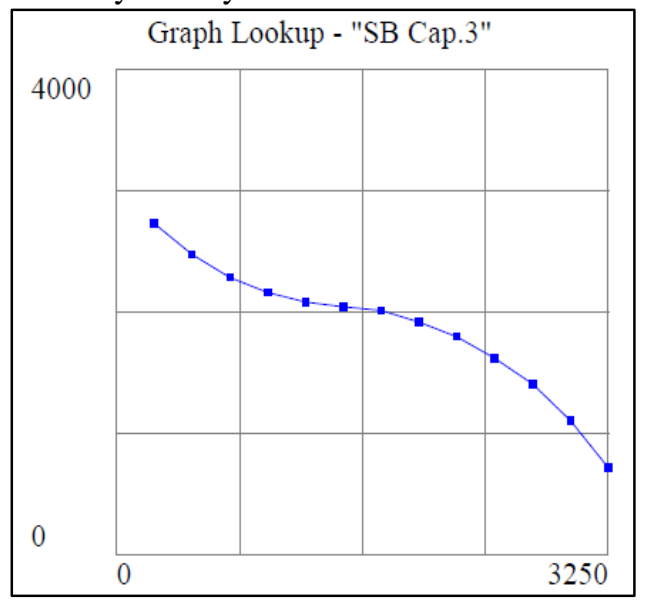

Figure 7: Lookup graph for the south bound entry capacity

\section{Calculations and Results Analysis}

The duration of the basic run of the system dynamics model in which all traffic data are fed as exogenous factors, each in due format as mentioned earlier, lasted for a period of 14 hours according to the data collection length and the time step was set to be 0.25 hour to resemble the 15 minute analyses period used in traffic data collection. This run yielded quite diversity in capacity estimates. Figure 8 shows the model outcome in which the pattern of capacity change along the modeling period and the difference in capacity estimates of the three utilized models for all approach entries.

In all these approach entries, the variable that estimates capacity according to the HCM 2010 method designated as (Cap-1) estimated the lowest capacity value and the Austroads method variable designated as (CAP-3) produced the highest capacity value, while the UK method variable designated as (Cap-2) came in between with a slight tendency towards (Cap-3) in the north bound entry influenced mostly by its geometry which has a great effect on the UK model among the others especially the entry yield line that the north entry has the widest one in the roundabout.

In another product of the model, capacities in each approach entry is represented graphically against its circulating flow. Capacity curves in these graphs resemble original curves presented in their derivation documents, as expected, what may reflect the proper simulation of the system dynamics model. The geometry influence is very pronounced in the UK method estimates what could be noticed in the proximity between (Cap-2) and (Cap-3) mentioned earlier, which could also be noticed clearly in Figure 9-a as compared to other curves.

The model also produced the degree of saturation as a measure of effectiveness in one of its outcomes where the change in the degree of saturation over time is illustrated graphically in a way that facilitates the comparison process. According to the HCM model variable that accounts for the degree of saturation designated (Sat. 1), the south entry exceeds the acceptable limit since the second hour of observation all the way to the end, while the north bound entry shows little less extreme degrees of saturation but still high and quite unacceptable as shown in Figure 10, a and c. The other two entries showed acceptable degrees of saturations except nearly 4 hours around the afternoon peak hour in the East bound and about 2 hours around the same peak for the west bound entry. These findings are rather excessive and does not reflect the field observations for if the degree of saturation is more than 1.0 for such continuous period, there would have been a very long and continuous queue all over the observation period which is not the case in this roundabout due to the limited capacity saturation minutes from which the field measured capacity observations are extracted and they were exactly $25,16,8$, and 12 for the south, north, west and east bound entries respectively. This may suggest that in general the HCM 2010 method often under estimate capacity in this case study.

As for the UK method saturation variable designated (Sat.-2), its patterns show that South bound entry is the most congested one where the degree of saturation exceeds the acceptable limit of 0.9 since the second hour of the observation and almost all the day long, while the in the East bound and the north bound entries it hardly reach this limit for only 
in the top of the afternoon peak. In the west bound entry, there was no congestion at all and the highest degree of saturation recorded is 0.727 at the peak hour.

Austroads method saturation variable labelled (Sat-3) estimates low values of the degree of saturation in all entries except in the north bound in which it exceeds the limit from 12AM until 5 PM. These results sounds a little under estimated as compared to the live observation where capacity saturated queues were witnessed in times other than afternoon peak hour, hence; a verification to the models outcome by the field measured capacity is necessitated.

In order to conduct a statistical tests, the capacity estimates resulted from the system dynamics model in three methods along with the field measured capacities are plotted on a chart inserted on an Excel sheet by which the data analyses were consulted to test the root mean square of errors (RMSE) for the scattered points of field capacities against the curve of each method in each entry. Figure 11 illustrates the three curves of the estimated capacities for each entry and their measured capacities. It could be easily noticed that the field capacities are closest to the UK method estimates with little tendency towards the HCM method in both east and west bound entries and with high proximity to the Austroads method in both north and South bound entries. Table 4 lists the RMSE for each entry and the average of entry flow throughout the observation period. It could be seen that the closest proximity between the field capacities and those estimated by the UK method for all entries due to the low RMSE but the other two methods altering this proximity as the percentage of the entry flow changes. When the entry flow is low and the degree of saturation is ranging within its acceptable limits, the HCM 2010 method capacity estimates are closer to the field measures than those estimated by the Austroads method, and on the other hand, when the flow is high and the entry is highly saturated, the Austroads method produces capacity estimates closer to the measured capacities.
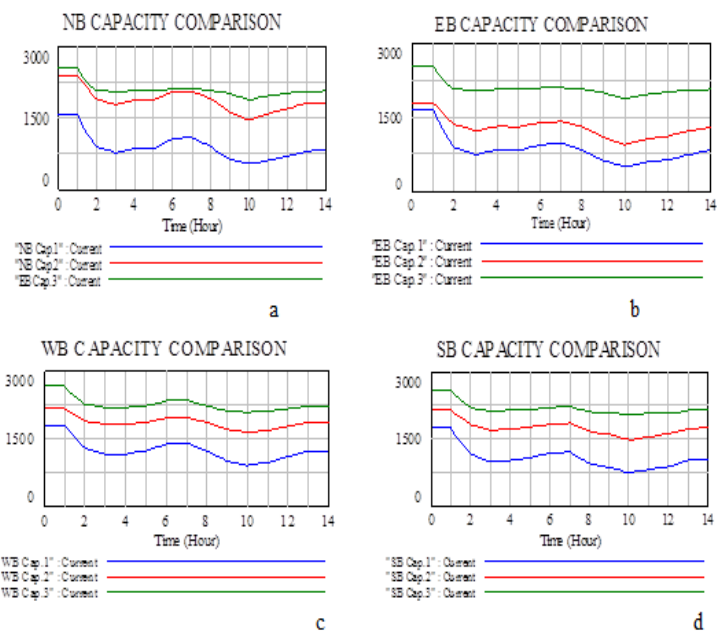

SB CAPACITY COMPARISON

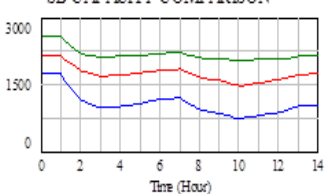

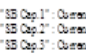

Figure 8: Patterns of capacity change over time
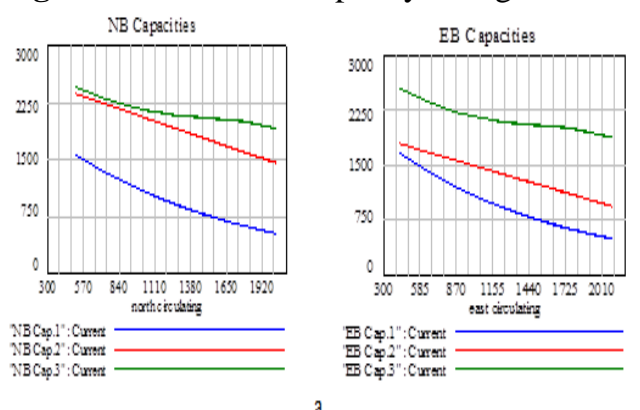

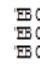

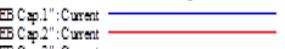

a

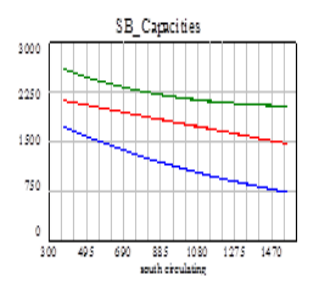

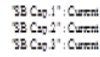

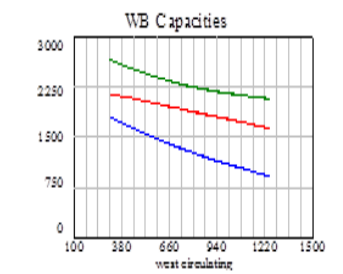

"WRCasp: : Curm

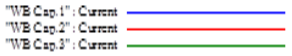

Figure 9: Capacity vs. circulating flow

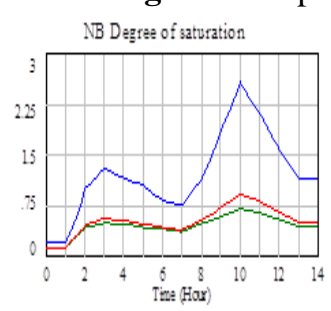

EB Degree of saturation
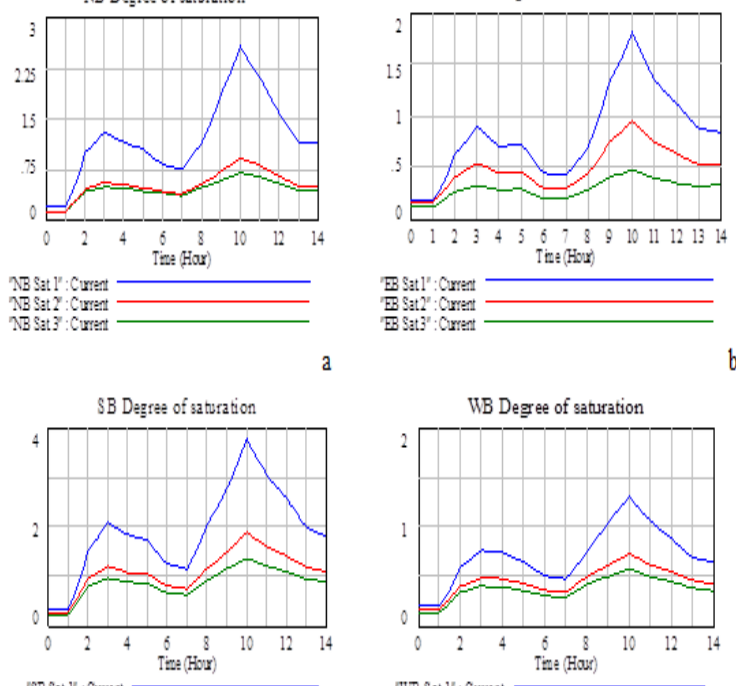

"SB Sat1" : Orrent

SBS Sat $y$ : Crreat

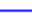

WB Degree of saturation

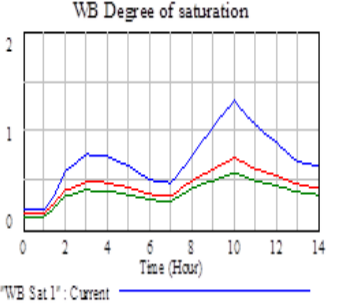

TWB Sat 1: Crrent

TWB Sat 2":Crent

Figure 10: Patterns of the change in degree of saturation over time 

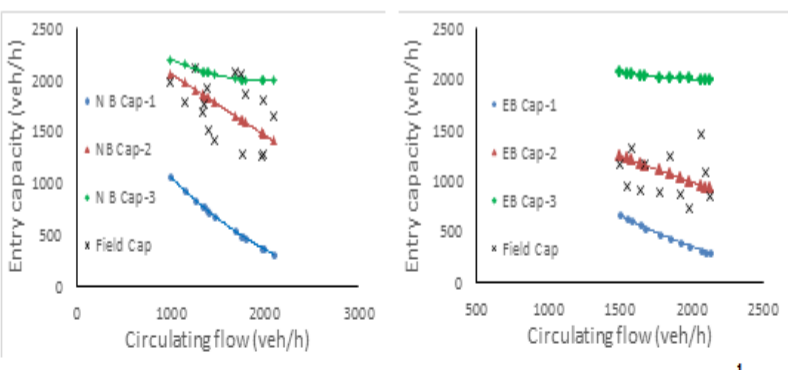

a
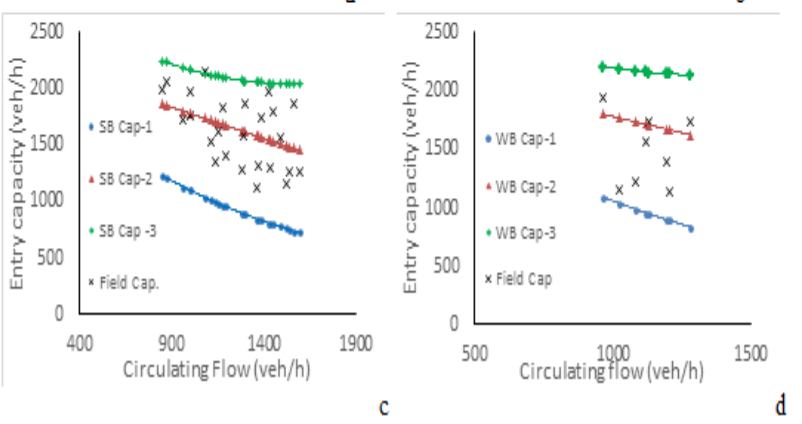

Figure 11: Field measured and estimated capacities

Table 4 Root mean square of error of field measured capacities to estimated capacities.

\begin{tabular}{|c|c|c|c|c|}
\hline \multirow{2}{*}{$\begin{array}{c}\text { Approach } \\
\text { Entry }\end{array}$} & \multicolumn{3}{|c|}{ Root mean square of enor } & $\begin{array}{c}\text { Averge percentage } \\
\text { of enty flow }\end{array}$ \\
\cline { 2 - 4 } & HCM 2010 & UK Method & Austoads & \\
\hline SB & 741.02 & 260.33 & 550.22 & $44 \%$ \\
\hline NB & 1132.16 & 272.47 & 428.18 & $22 \%$ \\
\hline IVB & 603.95 & 361.28 & 730.94 & $199 \%$ \\
\hline EB & 479 & 228.32 & 992 & $15 \%$ \\
\hline
\end{tabular}

\section{Conclusions}

In light of the results produced by the simulation model that incorporates the HCM, UK, and Austroads methods utilizing the case study set of data, the following conclusions could be carried out:

- The HCM 2010 method produced under estimated the capacity values for all entries and consequently raised the degree of saturation to some unacceptable limits for long continuous intervals represented about $85 \%$ and $71 \%$ of the observation period in the South and the North bound entries respectively. These congestions do not match the field observations.

- The Austroads method produced the highest capacities in all entries and consequently gave the least degrees of saturation, with the least fluctuation in their values both.

- The UK method produced the closest capacity estimates as compared to field measured capacities for they returned the least RMSE among other methods for all entries.

- The second closest estimates to the field capacities were produced by the Austroads method in the South and North bound entries which carried about $44 \%$ and $22 \%$ of the total traffic flow interred the roundabout respectively. While, on the other hand; the second closest estimates were produced by the HCM 2010 method in the West bound and the East bound entries which carried about 19\% and $15 \%$ of the total roundabout flow respectively.

\section{References}

[1].Lenters, M. and Rudy, C. HCM Roundabout Capacity Methods and Alternative Capacity Models. ITE Journal, 80 (7), (2010), 22-27.

[2].Robinson and Rodegerdts, Capacity and Performance of Roundabouts: A Summary of Recommendations in the FHWA Roundabout Guide, Transportation Research Circular E-C018: 4th International Symposium on Highway Capacity, Hawaii, 2000.

[3].National Cooperative Highway Research Program. NCHRP Synthesis 264: Modern Roundabout Practice in the United States. TRB, National Research Council, Washington, D.C., 1998.

[4]. RODEL User's Manual. Rodel Software Ltd and Staffordshire County Council, U.K, 2002.

[5].SIDRA User's Manual. Akcelik and Associates Pty Ltd, PO Box 1075G, Greythorn, Vic 3104,AUSTRALIA, 2000

[6].VISSIM 3.70 User Manual. PTV Planung Transport Verkehr AG: Karlsruhe, Germany, 2003.

[7].Bared, J.G., Edara, P.K., Simulated Capacity of Roundabouts and Impact of Roundabout Within a Progressed Signalized Road, Transportation Research Board, National Roundabout Conference, 2005.

[8].Ambadipudi, R., Modeling HighCapacity Multi-Lane Roundabouts, Transportation Research Board, National Roundabout Conference, 2009.

[9].Xuanwu C. and Ming S. L., A case study on multi-lane roundabouts under congestion: Comparing software capacity and delay estimates with field data" Journal of Traffic and Transportation Engineering (English Edition). 3, (2), Chang'an University, China. (2016), 154-165.

[10].Abbas, K.A., Bell, M.G.H., System dynamics applicability to transportation modeling. Transportation Research A, Vol $28 \mathrm{~A}, \mathrm{n}^{\circ} 5$, (1994), 373-400. 
[11].Raux, C., A systems dynamics model for the urban travel system, AET. European Transport Conference 2003, ETC 2003, 8 10 October 2003, Strasbourg, 2003, London, United Kingdom. AET, 32 p., 2003.

[12].Callejas Cuervo, M., Valero Bustos, H., Alarcón Aldana, A., Simulation Based on System Dynamics for Evaluating the Quality of Transport Service in A Complex Social System, Universidad Nacional de Colombia, Medellín, Colombia, Dyna, 80 (180), July-August, (2013), 33-40

[13].Xue W., Hudson C., System Dynamics Based Traffic Flow Simulation, Proceedings of SDS Conference, Oxford England, July 25-29, 2004.

[14].TRB. Highway Capacity Manual. Transportation Research Board. National Research Council, Washington DC, USA, 2010. ("HCM 2010")

[15].Kimber, R.M., The traffic capacity of roundabouts. TRRL Laboratory Report LR 942. Transport and Road Research Laboratory, Crowthorne, England, 1980.

[16].Federal Highway Administration. Roundabouts: An Informational Guide. U.S. Department of Transportation, Federal Highway Administration, FHWA-RD-00067, Washington, D.C., 2000.

[17].National Cooperative Highway Research Program. NCHRP Report 672:
Roundabouts: An Informational Guide, 2nd ed. Transportation Research Board of the National Academies, Washington, D.C., 2010.

[18].AUSTROADS. Roundabouts. Guide to Traffic Engineering Practice-Part 6: Roundabouts. Association of Australian State Road and Transport Authorities. Sydney, Australia, 1993.

[19].Akçelic, R., and R.J. Troutbeck. Implementation of the Australian roundabout analysis method in SIDRA, In Highway Capacity and Level of Service: Proceedings of the International Symposium on Highway Capacity (U. Brannolte, ed.), Karlsruhe, Germany. Rotterdam, Germany: Balkema Publisher, 1991, 17-34

[20].Transportation Research Board. Highway Capacity Manual. Special Report 209. Washington, D.C.: Transportation Research Board, National Research Council, 1994.

[21].Kumar, N., \& Umadevi, G., Application of System Dynamic Simulation Modeling in Road Safety. Retrieved August 10 , 2016 , fromhttp://onlinepubs.trb.org/onlinepubs/co nferences/2011/RSS/2/Kumar,N.pdf , 2011. 